\title{
El inconsciente colonial en la circulación del arte latinoamericano contemporáneo
}

\author{
THE COLONIAL UNCONSCIOUS IN THE CIRCULATION \\ OF CONTEMPORARY LATIN AMERICAN ART
}

La exposición como recolonización. Exposiciones de arte latinoamericano en el Estado español (1989-2010)

Francisco Godoy Vega Cáceres

Fundación Academia Europea

e Iberoamericana de Yuste, 2018, 461 páginas

La historia del arte contemporáneo en los últimos treinta años se ha enriquecido de una manera formidable al incorporar nuevos enfoques, marcos teóricos y objetos de estudio a su reflexión disciplinar. Consideramos que esta transformación se produce a la par de la crisis por el descentramiento de los límites del estatuto moderno de la obra de arte, la que, a su vez, se encuentra demarcada por la crisis en la historicidad del fenómeno artístico que se abre con la aparición y recepción de las vanguardias. La historia del arte, en este aspecto, ha empezado lentamente a asumir la sentencia de Adorno que inaugura su póstuma Teoría estética: "Ha llegado a ser obvio que ya no es obvio nada que tenga que ver con el arte, ni él mismo, ni en su relación con el todo, ni siquiera su derecho a la vida" (9).

El libro La exposición como recolonización. Exposiciones de arte latinoamericano en el Estado español (1989-2010), de Francisco Godoy Vega, es parte de una constelación de investigaciones que en la última 
década han venido a ampliar la discusión sobre los problemas del arte latinoamericano. Estas investigaciones, principalmente, se desmarcan del estatuto de la obra como objeto principal de la reflexión historiográfica y teórica para situarse en el ámbito de la producción, recepción y circulación de los discursos que organizan las posibilidades de inserción de las distintas obras que van componiendo el canon del arte latinoamericano, el que a su vez opera como un mecanismo de representación cultural.

Este libro de Godoy Vega, resultado de su tesis doctoral, se centra en un aspecto que es fundamental para comprender los recorridos del arte latinoamericano en el sistema artístico internacional desde los años noventa del siglo pasado: las estrategias expositivas. En este caso particular, el autor se centra en lo acontecido en el Estado espańol para plantear un enfoque que enriquece la discusión a ambos lados del Atlántico y que se presenta a partir de la conceptualización y la puesta en circulación "performativa", dice Godoy Vega, del arte latinoamericano en ese espacio múltiple.

Lo que se releva con esta propuesta no es llegar a un núcleo, a un centro específico que logre definir en qué radica el arte latinoamericano, en el sentido de saber cuáles son las características que le dotan de coordenadas de entendimiento y especificidad en el arte contemporáneo como una identidad determinada, sino que, por el contrario, es posicionarlo desde la perspectiva de la circulación y de la representación cultural que opera discursivamente "tras bambalinas". Este punto es uno de los importantes que encontramos en la exposición del autor, puesto que, si se toma desde el punto de vista de la representación cultural, es menester considerar la fundamentación ideológica que la sustenta en cuanto forma de ejercicio de poder que organiza y jerarquiza la realidad social (Chartier 56-57).

Por ello es que desde el título nos encontramos con la clave que va a organizar el relato: la exposición como recolonización da cuenta de la totalidad del proyecto que despliega este escrito, como una forma de lectura centrada en el reverso de la trama visible. Este se realiza a través de una recopilación documental profusa y profunda, mediante la cual Godoy Vega va delineando un recorrido interpretativo que permite establecer la configuración de un proyecto difuso -o por lo menos subterráneo- de (re)colonización a partir de lo simbólico y de lo cultural, 
mediante el establecimiento de un vínculo que aspira a reestablecer una modalidad imperial que España pierde desde fines del siglo XIX, con la independencia de los últimos territorios en América.

Esto último se materializa en el relato que organiza el autor a partir de las condiciones de circulación y recepción que se generan en la exposición, en tanto que dispositivo central de la dinámica del arte contemporáneo en su época global. Para ello, se organiza un marco teórico sólido que nos ofrece claves interpretativas a partir del rol de la curadoría, la imagen eurocentrada de América y su reconfiguración subalternizada como Latinoamérica, los problemas a los que se enfrenta la crítica postcolonial y sus políticas de representación, y el impacto de las políticas imperiales en la configuración del arte moderno a partir del establecimiento del canon moderno del arte.

Esto último nos resulta relevante de posicionar, puesto que si la historia del arte latinoamericano de los últimos treinta años se encuentra en los textos curadoriales, según señala Justo Pastor Mellado (11), esta se debería ampliar y plantear que la historia del arte latinoamericano en los últimos treinta años debe pensarse a través de las exposiciones que lo han configurado y marcado como una periferia productiva de los discursos artísticos que se organizan en los centros, no solo como un receptor de los desarrollos artísticos mismos, sino principalmente como un productor a la zaga y como proveedor de insumos discursivos.

Consideramos que esta estrategia de lectura que Godoy Vega realiza es de sumo interés y vitalidad, ya que no se centra solamente en la manera en que el arte latinoamericano ha intentado ganarse un lugar en la historia del arte de los centros. Buena parte de la reflexión curadorial e historiográfica latinoamericana de las últimas dos décadas ha experimentado y recorrido esta como una manera de generar un "correctivo ideológico" al esquema centro-periferia desde una perspectiva de flujos artísticos. Al contrario de estas reflexiones, el autor reconoce precisamente la manera en que la colonialidad funciona mediante la integración minorizada a su propia configuración discursiva.

Esta perspectiva nos permite posicionar a La exposición como recolonización como una crítica que avizora dos orillas mancomunadas. Primero, lo referente a la discusión sobre la situación del arte latinoamericano en los circuitos de circulación del sistema artístico internacional y la necesidad de su correcta representación, posición defendida preferiblemente 
por la curadoría de América Latina a partir de la recepción y desarrollo del discurso poscolonial, que se ha situado preferentemente en dotar a las "hablas nativas" de una capacidad de agencia en el sistema artístico internacional. Segundo, y ligado con lo anterior, las iniciativas de una semiperiferia como el Estado Español, que configura una imagen del arte latinoamericano que se distribuye a lo largo y lo ancho del sistema artístico internacional, y que compromete, a partir del establecimiento de filiaciones de distinto orden, la participación de agentes latinoamericanos para jugar a ambos lados del Atlántico.

Lo anterior genera que el interés español por el arte latinoamericano durante las últimas tres décadas no sea solamente un gesto que posiciona una representación correcta del arte contemporáneo de América Latina, sino que tiene que ver principalmente con la propia construcción que España se hace de sí misma para mostrar su modernidad. Si, como Godoy Vega nos plantea, la imagen atrasada que se construye de Espańa a partir de su deflación imperial ha intentado ser resarcida durante todo el siglo XX, en el arco de esta investigación (1989-2010) este trabajo se ve reforzado con la incorporación del arte latinoamericano a su propia construcción histórica. En cierta medida, podemos plantear a partir de esta indicación que la incorporación del "esclavo" al discurso del "amo" puede llegar a generar la idea de que el primero funciona en igualdad de condiciones con el segundo, pero, en la práctica, esta relación no se ve alterada, puesto que es el "amo" quien se reconstituye.

El recuento pormenorizado de exposiciones y el análisis exhaustivo que de ellas se realiza mediante el uso de documentación primaria logran generar y modelar la idea anterior, ya que dan luces sobre la forma material en que dicho mecanismo compensatorio funciona: el arte latinoamericano se incorpora a los flujos globales vía España y se conforma una imagen remozada, modernizada de esta a partir de la subsunción del arte latinoamericano como parte de una misma moneda. Así, exposiciones como Plus Ultra, en sus distintas modalidades; las que se dan cita en torno a las conmemoraciones del Quinto Centenario, las que componen el ciclo Versiones del Sur-organizadas por el Museo Nacional Centro de Arte Reina Sofía, y que revisten especial interés para el autor-, o Principio Potosí, dan cuenta de la maquinaria colonialista que esta publicación pone en la superficie, relevando así el "inconsciente colonial" que toma palco en la exposición. 
La exposición como recolonización. Exposiciones de arte latinoamericano en el Estado español (1989-2010) de Francisco Godoy Vega es una investigación que abre camino para nuevas vías de reflexión sobre el fenómeno del arte latinoamericano en su época global de circulación. Diversos elementos se pueden desprender de sus propuestas, principalmente porque aún existen demasiados vectores que se están observando de manera cada vez más compleja en la tensa relación entre Norte y Sur. Una interrogante que se proyecta desde el último capítulo es la relación entre sistema artístico internacional y economía transnacional desde una perspectiva que no tienda a una teoría de reflejo, asunto que es vagamente explorado en las investigaciones sobre el arte latinoamericano en el cambio de siglo y que perfectamente se podrían enfocar desde otros recursos teóricos, como la interrogación que diversos autores -ligados principalmente a la sociología- han realizado sobre el neoextractivismo como modelo de desarrollo, al cual la práctica artística parece estar respondiendo inconscientemente y cada vez más al pie de la letra.

Investigaciones de este espesor y con este tipo de enfoques son sumamente necesarias en la renovación del cuerpo disciplinar que es la historia del arte, principalmente desde la perspectiva de la apertura crítica en la construcción de corpus que excedan lo que acontece en las obras, sino que se posicionan desde lo que acontece con las obras y de las heterogéneas maneras en que estas son dispuestas en los discursos subyacentes al sistema artístico internacional en su etapa global. También hay que considerar que reflexiones de este talante no solamente son necesarias para pensar una renovación historiográfica en tanto cuerpo disciplinar de problemas, sino que, sobre todo, nos permiten situar críticamente las trayectorias del arte latinoamericano en el cambio al siglo XXI, manteniendo una serie de aporías en torno a la predominancia de la circulación como "el espacio" para que el arte de América Latina tenga algún lugar.

Pablo S. Berríos González

Universidad de Chile pabloberriosg@gmail.com 
BibLIOGRAFÍA

Adorno, Theodor. Teoría estética. Madrid, Akal, 2004.

Chartier, Roger. El mundo como representación. Barcelona, Gedisa, 2005. Mellado, Justo Pastor. "Historias de transferencia y densidad en el campo plástico

chileno (1973-2000)". Chile 100 años artes visuales. Tercer Periodo (19732000), Transferencia y densidad, Santiago de Chile, Museo Nacional de Bellas Artes, 2000, pp. 8-23. 